\title{
Condom Utilization and Associated Factors Among Female Sex Workers in Bahir Dar City Administration, Northwestern Ethiopia
}

\author{
Assefa Minwyelet ${ }^{1}$, Addisu Engdaw ${ }^{2}$ \\ ${ }^{1}$ College of Health Sciences, Mekele University, Mekele, Ethiopia \\ ${ }^{2}$ Addis Ababa Health Office, Addis Ababa, Ethiopia \\ Email address: \\ assefaminwyelet@gmail.com (A. Minwyelet),Addisuen1@Gmail.Com (A. Engdaw) \\ To cite this article: \\ Assefa Minwyelet, Addisu Engdaw. Condom Utilization and Associated Factors Among Female Sex Workers in Bahir Dar City \\ Administration, Northwestern Ethiopia. International Journal of Science, Technology and Society. Vol. 8, No. 5, 2020, pp. $113-121$. \\ doi: $10.11648 /$ j.ijsts.20200805.14
}

Received: August 20, 2020; Accepted: September 3, 2020; Published: September 10, 2020

\begin{abstract}
Condoms have dual method for Sexually Transmitted Infection (STI) and pregnancy prevention, but the usage is affected by several reasons. As we know, approximately 36.7 million people worldwide were living with HIV/AIDS at the end of 2016. Of these, 2.1 million were children $(<15$ years old). An estimated 1.8 million newly infected with HIV in 2016-about 5,000 new infections per day 160,000 children $(<15$ years). Most of these children live in sub-Saharan Africa. In Ethiopia, it is illegal to operate a brothel or procure sex workers as a commercial activity, but the sale of sex by women is not prohibited by law. The objective of this study was to assess condom utilization and associated factors among female sex workers in Bahir Dar city administration Northwestern Ethiopia. Community based cross sectional study triangulated with qualitative in-depth interview was conducted to determine condom utilization among 307 female sex workers in Bahir Dar city in February 2019 by using Face-to-face interview for quantitative and In-depth interview for qualitative part. Data was entered in to Epi-Info version 7 then, exported to SPSS version 23 for cleaning and analysis. Binary logistic regression analysis was used to determine the association between condom utilization and its associated factors. Then multivariable logistic regression model was employed to identify statistically significant variables for condom utilization (with $95 \%$ confidence interval and $\mathrm{p}<0.05$ ) for qualitative part till all questions answered and discussed with quantitative study. Condom utilization of Bahir Dar city commercial sex workers for the last one week was 170 (56.3\%) with a (95\% CI: 50.3-62.3\%). Those Respondents having negative Human Immune Virus result (AOR: 4.77, 95\% CI: 1.14, 20.102), having perceived social support (AOR: 3.84 95\%CI 1.326, 11.155). Literate (AOR: 12.95, 95\% CI: 5.22, 32.09) and those does not use drug (AOR: 5.94\% CI: 2.6, 13.55) were significantly associated with condom utilization. The qualitative study shows that sex worker perform sex without condom due to money. The current condom utilization among Bahir Dar city administration commercial sex workers is lower by considering their exposure to sexually transmitted infections so working by creating awareness about the severity of HIV infection and side effects of drug use and creating other job opportunity is more helpful.
\end{abstract}

Keywords: Condom Utilization, Female Sex Workers, Northwestern Ethiopia

\section{Introduction}

\subsection{Background}

Condoms have dual method for Sexually Transmitted Infection (STI) and pregnancy prevention, but the usage is affected by several reasons. As we know, approximately 36.7 million people worldwide were living with HIV/AIDS at the end of 2016. Of these, 2.1 million were children $(<15$ years old). An estimated 1.8 million newly infected with HIV in 2016-about 5,000 new infections per day 160,000 children ( $<15$ years). Most of these children live in sub-Saharan Africa. 1 million people died from AIDS-related illnesses in 2016 , bringing the total number of people who have died from AIDS-related illnesses since the start of the epidemic to 35.0 million [1]. Striking gains have been made towards 
many of the 2015 targets and elimination commitments, but still know there are significant challenges remain. Condom programming is an integral component of effective HIV prevention [2]. As the previous researcher said, from all female sex workers (FSW), pregnant women $92 \%$ of them lives with HIV and $90 \%$ of the world's children living with HIV are found in sub-Saharan. In 2011, in Sub-Saharan Africa $71 \%$ of all deaths were related to AIDS [3].

In Africa, female sex work may be stigmatized and illegal, and (FSWs) represent a marginalized section of the population. Poverty, inequality and female sex work (FSW) are relatively linked, because most workers of sex are female and they are economically poor. current research on the context of FSW in sub-Saharan Africa includes several important outcomes [4].

According to the 2016 Ethiopian Demographic and Health Survey (EDHS), based on a single point estimate, there are nearly 1.2 million people living with HIV/AIDS in Ethiopia. The adult prevalence rate is estimated at $2.4 \%$ and the incidence rate is $0.29 \%$. The prevalence and the incidence rates significantly vary by geographical areas and gender. For instance in urban the prevalence amount is estimated as $7.7 \%$, but the rural prevalence amount is small around $0.9 \%$, the prevalence rate for males are $1.7 \%$ and $2.6 \%$ for females [5]. Oral suggestions suggested that stigma attached to HIV and the resulting discrimination are critical barriers to achieve universal access to HIV related prevention, treatment, care and support in Ethiopia [6].

Make a profession or lives by procuring or on the prostitution or immorality of another, or maintains, as a landlord or keeper, a brothel, is punishable with simple imprisonment and fine. Traffic in Women and Minors.

Whoever, for gain, or to gratify the passions of another:

a) Traffics in women or minors, whether by seducing them, by enticing them, or by procuring them or otherwise inducing them to engage in prostitution, even with their consent; or

b) Keeps such a person in a brothel to make him out to prostitution, is punishable with rigorous imprisonment not exceeding five years, and fine not exceeding ten thousand Birr, subject to the application of more severe provisions, especially where there is concurrent illegal restraint [7].

The number of Ethiopian female sex workers is increase from time to time, the young girls and women entering to the sex trade are increasing. Public health programs and policies typically have emphasized HIV prevention in the vulnerable of population [8].

Sex worker women are being faced with stigma and discrimination in different forms of violence. the range of sources comes from clients, employers, community members, partners and other sex workers [7]. As shown in recent surveys, there has been a decrease in using condom and increase in the number of sexual partners in several parts of sub-Saharan Africa. Working to reduce the transmission of HIV and other STI related to sex work remain in sufficient. [2] It is an important issue to control HIV prevalence in sex workers and their clients. As an example of this, repeated sentinel surveillance showed that a decline in HIV prevalence has happened over seven years among female sex workers in some country in part, to prevention initiatives [9]. Using condom is effective in preventing of HIV if we use correctly and consistently and other STIs. The scientific evidence shows that male's condom have $80 \%$ or greater protective effect against STIs including HIV [10].

If the usage of condom becomes low in (FSWs), they will make things difficult by place themselves, their clients and the general population at risk of contracting HIV and other STIs since the female sex worker are the main transmitters in STI transmission dynamics. By hating the fact that the government has implemented different programs to create awareness in the society regarding to HIV/AIDS and apply different preventive methods, but still now in Ethiopia the infection rate remains high, especially among Most At Risk Populations (MARPs). Therefore, determining condom usage and sexual behavior of female sex workers would have a good contribution on targeting HIV prevention policies, programs, and strategies that would help to protect FSWs, their clients and the general population.

\subsection{Statement of the Problem}

Many female sex workers have risk factors for maternal morbidity and mortality, especially HIV-related mortality and complications, and death from unsafe abortions. However, little is known about the global impact of maternal morbidity and mortality on female sex workers compared with HIV and violence against them [11].

Sex work occurs to meet the demand for sexual services and become a universal phenomenon. In Africa sex work takes many forms and is an important source of income for many women even if sex worker reproductive health needs remain largely unmet. The criminalization of sex work, community and service provider stigma, violence, substance use and limited access to health services and prevention commodities contribute to the high HIV burden evident among female sex workers in Africa. Following United Nation program on HIV/AIDs (UNAIDS) three pillar approach to HIV prevention and sex work present an overview of current opportunities, barriers and suggestions to improve HIV prevention policy and programming for sex work in Africa. Universal access to a comprehensive package of HIV services is the first pillar. Reproductive health commodities, voluntary and anonymous HIV counseling and testing treatment of sexually transmitted infections, HIV and opportunistic infections, harm reduction for substance use and psychosocial support services make up the recommended package of services. The second pillar is a sex worker supportive environment. The inclusion of sex worker programmers within national HIV strategic planning; sex worker lead community mobilization and the establishment of sex work community networks (comprised of sex workers, health service providers, law enforcers and other stakeholders) enable effective programmed implementation and are recommended [12]. The reduction of sex worker vulnerability and addressing structural issues form the final pillar. The decriminalization of sex work development of 
supportive policy gender equality and economic development are key factors that need to be addressed to increase sex worker resilience. Evidence supports the public health benefit of human rights based approaches to HIV prevention; moralistic and restrictive policy and laws towards sex work are harmful and should be removed. The establishment of these pillars will increase sex worker safety and enhance the inclusiveness of the HIV response [12]. 2015 National MARPs Survey, HIV prevalence among FSWs National-23\% Bahir Dar-32\%, Kombolcha-29\%, Metema-17\%. Finally the researcher stands to assess their problem because of limited study area as well as topic and to show their problem for concerned part.

\subsection{Significance of the Study}

As there is limited study in the area, the research data show the difficulty and necessary of the problem of the prevalence of STI and HIV/AIDS. Most of the time female sex workers are referred as a core population who are in a deep (MARPs) risk and sources for HIV transmission because of different reason like having low economic status, having more than one sexual partner, and big challenges related to using condoms consistently. There for, the finding of this research will help female sex workers by solving these problems. This research may also encourage and give support for the Bahir Dar city administration and NGOs through giving detail information on how to prevent HIV/ADIS, use of condoms, and the number of FSW. Since this research gives a great attention to the reproductive health system preventing STI, HIV and unintended pregnancy, and complication and interest in fertility for female sex workers, this study may increase the health of female sex worker. Generally the findings of this study may put some spots on the life of people who are working as female sex worker, for policy makers, for researchers and programmer as a bench mark for their further deeds.

\section{Objective}

\subsection{General Objective}

To assess condom utilization and associated factors among Female sex worker in Bahir Dar city administration, Northwestern Ethiopia

\subsection{Specific Objective}

1) To determine condom utilization among female sex worker in Bahir Dar city administration.

2) To find out the factors affecting the use of condom among female sex workers in Bahir Dar city administration.

\section{Methods}

\subsection{Study Design}

Community based cross sectional study design triangulated with qualitative in depth interview approach was conducted.

\subsection{Study population, Area and Period}

The study was conducted in Bahir Dar city Feb, 2019. Bahir Dar is the capital city of Amhara regional state located $592 \mathrm{kms}$ away from Addis Ababa on northwest Ethiopia. According to Bahir Dar city administration report Bahir Dar city has 249, 429 total population of which 179, 715 female. There are 12 Government health facilities (one referral hospital, one primary hospital and ten health centers) and 21 private health facilities (three general hospital and 18 medium private clinics) those are serving preventive, curative and rehabilitative service. In Bahir Dar there are 989 formally registered commercial sex workers. They are mainly found in drinking establishments, night clubs, bars, and majorly known pensions based on the information obtained from ministry of labour and social affairs of Bahir Dar city administration in 2019. The study population was female sex workers lived in Bahir Dar city administration The source population for this Study was selected female sex workers who lived in Bahir Dar city administration.

\subsection{Inclusion and Exclusion Criteria}

\subsubsection{Inclusion Criteria}

All female sex workers live in Bahir Dar city administration.

\subsubsection{Exclusion Criteria}

Those who are seriously sick and unable to communicate during data collection time were excluded and who were menstruating in data collection time.

\subsection{Study Variables}

\subsubsection{Dependent Variable}

Condom utilization (Yes/ No)

\subsubsection{Independent Variables}

Socio-demographic Factors: Economic status/Income, educational status, age, Religious

Ethnicity, Marital Status

Personal factors: substance use, alcohol use, attitude, knowledge

Social support, viability of condom price, shortage Customer/ Clients' high payment, substance user, force

Health status: HIV carrier, History of STI.

\subsection{Operational Definitions}

Condom utilization: is defined as the consistence use of a condom on the last one week sexual intercourse.

Availability of condom: Good when they can get at time.

Perceived social support: Based on Oslo By summarizing the raw scores, the sum ranging from 3-14. A score of 3-8 is "poor support", 9-11 is "moderate support" and 12-14 is "strong support".

Attitude towards condom: By summarizing the raw scores the sum 11 and below have "good Attitude", and the sum 
greater than 12 "poor Attitude".

Alcohol intake: Based on WHO measurement, If the individual drinks 1 up to 2 beer per day "low drinker", if the individual drinks $>2$ "high drinker".

\subsection{Sampling Techniques and Sample Size Determination}

For quantitative part to determine the sample size of the population, single population proportion formula was used to calculate sample size by considering the following assumptions proportion of condom utilization among FSW $(p)=47.74 \%, 95 \%$ confidence level, 5\% marginal error [13].

$$
\begin{gathered}
\mathrm{n}=(\mathrm{Z} \alpha / 2)^{2} * \mathrm{P}(1-\mathrm{P}) / \mathrm{d}^{2} \\
\left.\mathrm{n}=(1.96)^{2} *(0.47)(1-0.47) / 0.05\right)^{2}=383.37
\end{gathered}
$$

By using correction formula $\mathrm{n}=\mathrm{N} / 1+\mathrm{N} / \mathrm{n}=277$

Then, by adding $10 \%$ non-response rate, the final sample size $(\mathrm{n})=305$ FSWs

However, to obtain a better sample size I used to calculate by factors [table 1].

\begin{tabular}{|c|c|c|c|}
\hline No & Factors for sample size calculating & Used & Size \\
\hline 1 & Awareness STI will increase HIV infection rate & $\begin{array}{l}95 \% \text { CI, } 90 \% \text { Power ratio } 1 \text {, control exposed } 46 \% \text { odds ratio } 7.8 \text {, case with } \\
\text { exposure } 87 \%[18]\end{array}$ & 69 \\
\hline 2 & Tested HIV in the last 12 months & $95 \%$ CI, $90 \%$ power, ratio 1 , Control exposed $36 \%$, Case with exposure $93 \%$ [18] & 43 \\
\hline 3 & $\begin{array}{l}\text { HIV/STI transmission \&prevention method knowledge } \\
\text { computed variable }\end{array}$ & $95 \%$ CI, $90 \%$ power, ratio 1 , Control exposed $78 \%$, Case with exposure $54 \%$ [18] & 194 \\
\hline 4 & Perceiving at risk of getting HIV & $95 \%$ CI, $90 \%$ Power, ratio 1 , Control exposed $44 \%$, Case with exposure $30 \%$ [18] & 307 \\
\hline 5 & Based on prevalence and correction formula & {$[18]$} & 305 \\
\hline
\end{tabular}

Table 1. Sample size calculation by factor.

The final sample size determined including $10 \%$ nonresponse rate was 307 and 5 for qualitative part from city administration, local NGO, merchants and government employee male and female. Simple random sampling method was used. From the list of registered female sex worker on Local NGO (Mahiber Hiwot) Bahir Dar branch work on female sex worker HIV/ADIS and other related problem. Legality was assured for female sex worker and NGO by using ethical clearance paper which was obtained from Bahir Dar University. The confidentiality was kept by collaborate with local NGO. The residences of the participants were addressed by data collector using registered addressee. The data collector selected from sex workers from different area which is highly condensed to find easily. The principal investigator was interviewing those having direct related to sex workers by selecting randomly.

\subsection{Data Collection Procedure and Instrument}

For quantitative the instrument was prepared by referring relevant literature and by adopting similar instrument used earlier. The questions were first translated to Amharic and distributed to the clients then back to English for analysis. For qualitative Face-to-face interview was applied using a structured questionnaire in-depth interview guide line, tape recorder, not book and pen. For both two nurses who have an experience of supervision in similar data collections were selected as supervisors. Training was provided for one day on the overall data collection activities by the researcher. The researcher recruited six persons who are working in local NGO (Mahibere Hiwot) as data collector with educational level of degree, whoever participated in data collection activities. Moreover, the data collector used the Amharic version for collecting the data that includes the whole sex workers registered on mapping document. The collection of the data was took place between 3:00 AM-6:30 AM local time through from house to house tracing where they are living

For qualitative data: Making quite environment adjusting recorder then record.

\subsection{Data Quality Control and Analysis}

A pretest or pilot survey was conducted with 31 female sex workers in Finote Selam town before the main survey. The aim of the study was briefly discussed to ensure the data collectors familiar with the aim of the study and data collection processes. The filled questionnaire was checked daily by the supervisors and the principal investigators for completeness and accuracy. Any obstacles or issues that were arisen at the time of data collection was discussed at 9:00 PM up to 11:00 PM with data collectors and the supervisors, were resolved. For quantitative part the data was coded and entered into Epiinfo version 3.5.3 and then it was transferred to SPSS version 23.0 software package. Logistic regression analysis was used to determine the association between different factors and condom utilization. The results of this study were presented in the form of tables and texts using frequencies and summary statistics such as standard deviation and percentage to describe the study population in relation to relevant variables. Odds ratio with $95 \%$ confidence interval was used to identify the independent predictors of condom utilization. For the qualitative part, data collected interviews was transcribed and cleaned manually before being recorded into the computer. Then, these data was coded and categorized using open code software version 3.4 .

\section{Result}

\subsection{Socio Demographic Characteristics Study Participants}

Out of the total 989 registered commercial sex workers in the city 307 were included in the study resulting in a response rate of $302(98.37 \%)$. The mean age of participants was $27.66 \pm 4.55$ years. Almost half of, 137 (45.3\%), the 
participants were bar-based sex workers, and about 3.3\% were street-based workers. The average years of the respondents who were working in the area was $4.84 \pm 3.096$ years.

Additionally the respondents $253(83.8 \%)$ were orthodox, $28(9.3 \%)$ protestant, and followed by $20(6.6 \%)$ muslin. The remaining and $0.3 \%$ were catholic. In terms of educational level, $116(38.4 \%)$ participants were unable to read and write $186(61.6 \%)$ literate. About $121(40.1 \%)$ of respondents included in the study had been unemployment before they joined their current work. The average customer per day was $4 \pm 3.07$, and average daily income is $461.95 \pm 350 \_$ETB. Fifty five percent had started sex under the age of 18 years old. When we see reason of having sex for the first time, $38.1 \%$ were due to friendly, $22.2 \%$ marriage, violence $20.5 \%$ and $19.2 \%$ due to income [table 2].

Table 2. Socio demographic characteristics of female sex workers in Bahir Dar city Administration northwestern Ethiopia February 2019.

\begin{tabular}{llll}
\hline & Variables (N =302) & Frequency & Percentage \\
\hline \multirow{4}{*}{ Marital status } & Single & 176 & 58.3 \\
& Married & 4 & 1.3 \\
& Windowed & 41 & 13.6 \\
& Separated & 2 & 0.66 \\
& Divorced & 79 & 26.2 \\
Educational level & Unable to write\& Read & 116 & 38.4 \\
& Literate & 186 & 61.6 \\
& Bar based & 137 & 45.4 \\
Type of sex work & Home based & 113 & 37.4 \\
& Phone based & 42 & 13.9 \\
& Street based & 10 & 3.3 \\
& Amhara & 199 & 65.9 \\
Ethnicity & Agew & 63 & 20.9 \\
& Tigray & 20 & 6.6 \\
& Oromia & 14 & 4.6 \\
& Other & 6 & 2.0 \\
Age first sex & $>18$ & 136 & 45.0 \\
& $<18$ & 166 & 55.0 \\
Reason for $1^{\text {st }}$ sex & Friendly relationship & 115 & 38.1 \\
& Violence & 62 & 20.5 \\
& Income & 58 & 19.2 \\
& Marriage & 57 & 18.9 \\
\hline
\end{tabular}

\subsection{Condom Related Response, Knowledge About HIV/AIDs and STI Transmission and Prevention Methods}

Almost all of the respondents' knew about condom. The source of condom information they heard, 93\% from friends, $74.5 \%$ from health institution, $39.1 \%$ from radio, $11.3 \%$ from television and $5.6 \%$ were from newspaper. Two hundred sixty seven $(88.4 \%)$ of the respondents had knowledge about HIV and STI transmission and prevention methods. The respondents knowledge on preventing methods use condom $260(86.1 \%)$, abstain from sex $44(14.6 \%)$, and be faithful 21 (7.0\%). Respondents two hundred thirty nine (79.1\%) have good attitude towards condom. One hundred twenty four $(41.1 \%)$ of the respondents had been married before they entered to sex work, of which $79(26.2 \%)$ were divorced and $43(14.2 \%)$ were windowed. In the past six month female sex worker Sexual Transmitted Disease prevalence were 50
(16.6\%). 22 (7.28\%) develop genital ulcer, 19 (6.29\%) vaginal discharge, $8(2.6 \%)$ lower abdominal pain and $5.6 \%$ was other STI disease.

Regarding the number of sexual partners, 255 (84.4\%) participants reported that two or more sexual partner per day. $57(18.9 \%)$ of sex workers had anal sex [Table 3].

Table 3. Condom related source, price and perception of female sex workers in Bahir Dar city Administration northwestern Ethiopia February 2019.

\begin{tabular}{|c|c|c|c|}
\hline Variable & Category & No & Percentage \\
\hline \multirow{5}{*}{$\begin{array}{l}\text { Source of information } \\
\text { on condom }\end{array}$} & Friends & 281 & 93 \\
\hline & Health Institution & 225 & 74.5 \\
\hline & Radio & 118 & 39.1 \\
\hline & TV & 34 & 11.3 \\
\hline & News Paper & 17 & 5.6 \\
\hline \multirow{2}{*}{ Condom Slipped } & Yes & 22 & 7.3 \\
\hline & No & 270 & 92.7 \\
\hline \multirow{2}{*}{ Condom Breakage } & Yes & 36 & 11.9 \\
\hline & No & 266 & 88.1 \\
\hline \multirow{6}{*}{ Source to get Condom } & Privet pharmacy & 226 & 74.8 \\
\hline & Health center & 72 & 23.8 \\
\hline & Shops & 62 & 20.5 \\
\hline & Pensions & 47 & 15.6 \\
\hline & Government hospital & 46 & 15.2 \\
\hline & Other & 30 & 9.9 \\
\hline \multirow{2}{*}{$\begin{array}{l}\text { Perception to use } \\
\text { condom correctly }\end{array}$} & Yes & 210 & 69.5 \\
\hline & No & 92 & 30.5 \\
\hline \multirow{2}{*}{ Decision maker } & I & 103 & 34.1 \\
\hline & Customer & 199 & 65.9 \\
\hline \multirow{2}{*}{$\begin{array}{l}\text { Price of condom } \\
\text { afford }\end{array}$} & Yes & 80 & 26.5 \\
\hline & No & 222 & 73.5 \\
\hline
\end{tabular}

\subsection{Community Support, Additional Work and Reason for Leaving Birth Place}

Regarding Community support, 197 (65.2\%) poor support, while $92(30.5 \%)$, only $13(4.3 \%)$ mild and got strong support respectively. $57(18.9 \%)$ perform anal sex. On the other hand their reason for leaving place of birth $44.7 \%$ by family collapse, $120(39.7 \%)$ screeching better life, 22 $(7.3 \%)$ fear of early marriage, $12(3.97 \%)$ was by war, and the remaining $13(4.3 \%)$ were other causes for leaving the birth place. When asked the frequency of using condom with their steady partner, $117(38.7 \%)$ respondents responded as though they practiced it always, while 158 (52.3\%) and 27 $(8.9 \%)$ respondents disclosed as if they practiced condom sometimes and never respectively. The frequent customer that face frequently were $253(83.8 \%), 173(57.3 \%), 135$ (44.7\%), $39(12.9 \%)$ and $35(11.6 \%)$ merchant, long truck driver, soldier, student and other respectively. Likewise, in terms of additional work they have $76(25.2 \%)$ had additional work $2(0.7 \%)$ micro and small activities, $5(1.7 \%)$ daily laborer, $13(4.3 \%)$ waiter, $47(15.2 \%)$ coffee and tea house, home to home servant $1(0.3 \%)$, and $10(3.3 \%)$ had other work. In terms of the Challenges female sex worker had face, the responded that $43(14.2 \%)$ were disturbed by intoxicated person, refused to pay $233(77.2 \%)$, refused to use condom $69(22.8 \%)$, hit by customer $189(62.6 \%)$ and $4(1.3 \%)$ faced other problem. All female sex workers take alcohol [Table 4]. 
Table 4. Drug use, alcohol intake, HIV result and ART related characteristic of female sex workers in Bahir Dar city Administration northwestern Ethiopia February 2019.

\begin{tabular}{llll}
\hline Variable & Category & Number & Percent \\
\hline \multirow{2}{*}{ Additional work } & Yes & 76 & 25.2 \\
& No & 226 & 74.8 \\
Drug use & Yes & 131 & 43.4 \\
& No & 171 & 56.6 \\
Alcohol intake & Low drinker & 131 & 43.3 \\
Believe on risk for & High drinker & 171 & 56.6 \\
HIV & Yes & 170 & 56.3 \\
HIV test & No & 66 & 21.9 \\
& Yes & 276 & 91.4 \\
Result & No & 26 & 8.6 \\
& Positive & 81 & 26.8 \\
ART start & Negative & 195 & 64.6 \\
& Yes & 70 & 23.2 \\
\hline
\end{tabular}

NB= ART, Anti Retro Viral Therapy STI, Sexually Transmitted Infection.

\subsection{Condom Utilization}

Quantitative part regarding condom utilization were 170 $(56.3 \%)$. the reasons they suggested for not using condom is high payment $102(33.8 \%)$, due to love $3(1.0 \%)$ customer intoxicated $4(1.3 \%)$, self-intoxicated $29(9.6 \%)$, use force by customer $52(17.2 \%)$, out of safe period for pregnancy 14 (4.6\%) for satisfaction $8(2.6 \%)$. For the last sexual activities (current utilization) condom utilization was 218 (72.2\%). Fifty seven (18.9\%) of the respondent can get condom when they want.

Qualitative part 25 years old female sex worker said that "performing sex for a case of money is known as sex worker. Low educational level, lack of access to work and peer influence are some of the reason for entering sex worker. Ohoho... the community thinks about sex worker like devil. There are drinking alcohol, substance user finally have low self-esteem. It is challenging but they will change the work style. Hopelessness and sake of money are the major reason for sex without condom regarding sex worker and according to male intoxication and condom will decrease satisfaction are the reason not using condom. From living as such like if they can get chance they will change this work. As my thought community mobilization government involvement including sex worker initiation for change are the solution to solve their problem."

31 years old sex worker said "sex worker mean having multiple sexual partner for business called sex worker. Peer influence and low income are some of the reason for starting sex worker. The community totally considers as sin and didn't want communicate even parents. Sex worker have different behavior like angriness, disaffirm and drinking alcohol. They may change if they get the chance, some of sex worker may change but they should not consider easy it needs continuous follow up. At the time of drinking alcohol and using substance they didn't use condom. Generally to solve this problem showing the challenge of sex worker for the rest community may minimize new entrance."
26 years old who is sex worker "having sex for money for a long time is definition of sex worker. Early marriage, family collapse and low income are some of the case for sex worker. The community think they are special person having their own attitude due to this the community ignored them. Sex worker have "live for today" like attitude they don't care for tomorrow additionally they are drinker, chat chewer, risk for different psychological disorder. Definitely they have idea to change their work we have discussed so many times. They have idea for other work. There are drinker, substance user and haven't idea for care them self-due to this they didn't use condom. Government leaders and religious leader jointly give continues training for attitudinal change."

33 years old sex worker "use sex for sources of money on day to day activities. Community ignorance, low educational level, fear of early marriage and family collapse are some of the reason leading factors for sex worker. The community didn't understand the back history instead of this they avoid from including social interaction even at the time of illness. Sex worker have unstable working area due to this they have different behavior liker drinker, inferiority, sense of ignored by the community and pessimist ideology. If they get comfortable environment automatically they will change their attitude, who want live out of community involvement or out of social interaction so they will change. For the case of money they didn't use condom. Community and government should create smooth relation other working environment respectively."

25 years old female sex worker said that "female sex worker mean doing sex for the case of money. The reason for doing sex is family collapse, low school level, peer influence and others. The community understands in two way which is positive and negative that is according to closeness with sex worker. On sex worker every fee used by a day for drinking, for substance, and eating finally they have no future plan. Searching better life is the reason for leaving place of birth. Really first if the community create positive relation and fee for small business activities automatically majority of sex worker will shift from this work. Due to drug and unable to use condom correctly are the reason of sex workers and loss of satisfaction and drinking alcohol are the reason for performing sex without condom. To the problem government involvement is better to solve the problem and improve their life".

\subsection{Factors Associated with Condom Utilization Among Female Sex Workers}

In the bi-variate logistic regression analysis having children, perceived risk for HIV, daily beer intake, decision to use condom during sexual intercourse, perception to use condom correctly and attitude towards condom were significant at $\mathrm{p}$-value $<=0.2$. However, in the multiple logistic regressions, only drug use, perception to use condom correctly, Educational level and social support remained as a statistically significant factor for condom utilization. Those FSWs who reported not taking drug can increase condom utilization had about 5 times higher odds of using condom 
than those who had taken drug (AOR: 5.94, 95\% CI (2.6, 13.55)). Those FSWs who did have social support to use condom about 4 times than they can't get support (AOR: 4.0, $95 \%$ CI $(1.38,11.60))$. FSWs who perceive using condom correctly had about 7 times higher odds of using condom than those who did not perceives use correctly (AOR: 7.099, 95\% CI $(1.885,13.81))$. Those FSWs who is educated 13 times higher odds of using condom than who were unable to read \& write (AOR: $12.95,95 \%$ CI $(5.22,32.09)$ ) [Table 5].

For qualitative data low knowledge about the use of condom correctly, hopelessness, using alcohol and substance are the reason for not using condom during sex on the side of sex worker, on male side intoxication and condom will decrease satisfaction are the reason for not using condom.

Table 5. Factors associated with Condom utilization of female sex workers in Bahir Dar city Administration northwestern Ethiopia February 2019.

\begin{tabular}{|c|c|c|c|c|c|}
\hline \multirow{2}{*}{ Variable } & \multicolumn{2}{|c|}{ Condom utilization } & \multirow{2}{*}{ Crude Odds Ratio (95\%) } & \multicolumn{2}{|c|}{ Adjusted Odds Ratio } \\
\hline & Yes & No & & AOR (95\% CI) & P-value \\
\hline \multicolumn{6}{|l|}{ Use drug } \\
\hline Yes & 134 & 37 & 1 & $5.94(2.6,13.55)$ & $<0.001$ \\
\hline No & 36 & 95 & $9.557(5.632,16.21)$ & & \\
\hline \multicolumn{6}{|l|}{ Perceived social support } \\
\hline Yes & 83 & 22 & $4.77(2.758,8.249)$ & $4.0(1.38,11.60)$ & 0.010 \\
\hline No & 87 & 110 & 1 & & \\
\hline Literate & 154 & 32 & $30.07(15.69,57.66)$ & $12.95(5.22,32.09)$ & $<0.001$ \\
\hline Unable to write $\&$ read & 16 & 100 & 1 & & \\
\hline \multicolumn{6}{|l|}{ Perceive using condom correctly } \\
\hline Yes & 160 & 50 & $26.24(12.6,54.4)$ & $7.09(1.78,13.81)$ & 0.002 \\
\hline No & 10 & 82 & 1 & & \\
\hline
\end{tabular}

Abbreviations: COR, crude odds ratio; CI, confidence interval; AOR, adjusted odds ratio.

\section{Discussion}

The objective of this study was to determine the prevalence and associated factors of condom utilization among commercial sex workers in Bahir Dar city administration by the year 2019. The findings of this study showed that the overall prevalence of condom utilization was $56.6 \%$ with confidence interval 50.3 up to $62.3 \%$. This is consistent with a study conducted in Savannakht Thailand among sex workers, where the utilization of condom was $60 \%$ the reason may due to similar knowledge about condom including source of information [15].

And this study finding was higher than study conducted in Switzerland $24 \%$ the probable reason may be due to $48 \%$ of women had experienced condom failure with any partner and they use emergency contraceptive [14]. This study is higher than the study conducted in Finote Selam town (47.7\%) the difference may due to difference in the duration of the study and the interventions used for the target group [17]. However, the finding of this study was lower than that from Mexico which reported $85 \%$ [16]. The probable reason for this discrepancy might be increased female decision making power and increased educational level.

Those FSWs who reported not taking drug increase condom utilization had about 5 times higher odds of using condom than those who had taken drug. This study supported by the study Haramaya University Students, Ethiopia not taking substance 2.58 times odds ratio using condom confidence interval $(1.58,4.22)$ [30]. Having a drug-using partner was another exposure for inconsistent condom use in this study and the risk was realized in two ways Emory University North America 2017 [19]. Additional study which support drug use were decrease use of condom the study conducted in Malawi 2017 [20] the cause may be drug decrease decision making habit.

On qualitative study 25 years old sex worker says "Due to using drug perform sex without condom." 33 years old sex worker "at the time of drinking alcohol and using substance they didn't use condom." 26 years old who is sex worker "substance user due to this they didn't use condom."

Those FSWs who did have social support to use condom about 4 times higher odds ratio than they can't get support. This study finding were supported by the study conducted in Jimma zone, South west Ethiopia having family support 0.921 times odds ratio for risk sexual behavior with CI. (0.91-0.96) [21]. Additional study in china lower levels of public stigma were associated with consistent condom use 0.19 [22]. Perceived social support 0.39 was significant China 2014 [23]. Other study having social support 0.197 odds ratio which protective effect research conducted in Nigeria [24]. Perceived social support for condom use from peers, parents and non-parental figures in the community was associated with higher odds of condom use Southwest Nigeria [25]. this might be due to social support increase future hope so they utilize condom.

On qualitative study 25 years old female sex worker said "Hopelessness was major reason for sex without condom. 26 years old who is sex worker "haven't idea for care them selfdue to this they didn't use condom."

Those FSWs who is educated 13 times higher odds of using condom than who were unable to write and read. This result is supported by the study conducted in high educational level Seven urban centre's in Ethiopia 0.59 times odds ratio protective effect of exposed for risk sexual behaviors $(0.37,0.93)$ [27], other area in Malawi 2017 [20]. Low Educational level have 0.142 odds ratio research conducted Nigeria 2017 [24]. Based on the reports from 
women condom use was associated with higher educational level of the female partner in with odds ratio 2.6 on subSaharan Africa [26]. Ethiopian behavioral surveillance surveys female sex worker who unable to write and read Odds ratio 0.17 use condom consistently this may be due to increase knowledge and attitude when they have education [27]. Additional study conducted in Gondar University Hospital, 23.93 times odds ratio of using condom [28].

FSWs who perceive using condom correctly had about 7 times higher odds of using condom than those who did not perceives use correctly. This might be due to confidence they are using correctly female sex worker have interest to use frequently. Supporting study conducted in Debre Work, East Gojjam Zone, Amhara Region Ethiopia 4.37 times odds ratio of using condom with CI. $(2.85,6.71)$ [29].

From qualitative study 25 years old female sex worker "unable to use condom correctly is the reason of sex workers reason for performing sex without condom."

\section{Conclusion}

The current condom utilization among Bahir Dar city administration commercial sex workers is lower which were $170(56.3 \%)$ having perceived perfect condom use, being Literate and those does not use drug were significantly associated with condom utilization, Bahir Dar city Health Office in collaboration with Non-governmental organizations in the area should work on creating awareness about the severity of the disease and side effects of drug use.

\section{Recommendation}

1) The city administration and Zone Health Office in collaboration with Non-governmental organizations in the area should work on creating awareness about HIV positive result increase utilization to decrease viral load, reducing daily beer intake by educating the effect of alcohol on condom utilization, zonal health center collaborating with labor and social affairs minimize the prevalence of drug use,

2) Bahir Bar city administration by community mobilization increase social support.

3) Schools those found in the city give opportunity education and increase their educational level because these factors have significant association.

4) Zonal Health institute should addressee ART for those not in ART by counseling.

5) Researcher should study the correctness of utilization by using doll.

\section{References}

[1] UNAIDS, UNAIDS report on the global AIDS epidemic UNAIDS Report, 2016: p. 198.

[2] FMOH, Country Progress Report on HIV/AIDS Response. BMC health service research, 2012. 1 (1): p. 138.
[3] Gallinetti, J. and D. Kassan, Trafficking ofChildren inAfrica: An Overview of Research, International Obligations and Existing Legal Provisions. Children's Rights in Africa: A Legal Perspective, 2013.

[4] Longo, J. D. D., et al., Spectrum of female commercial sex work in Bangui, Central African Republic. SAHARA-J: Journal of Social Aspects of HIV/AIDS, 2017. 14 (1): p. 171-184.

[5] International, C. I., Ethiopian Demographic and Health Survey 2016. Addis Ababa, Ethiopia and Calverton, Maryland, USA, 2017 (just-accepted): p. 551.

[6] UNAIDS, the people live with HIV stigma index in Ethiopia UNAIDS Report, 2011: p. 96.

[7] FDRE, The Criminal Code of the Federal Democratic Republic of Ethiopia 2004. p. 282.

[8] Overs, C., et al., Sex work in Ethiopia: Mapping the impact of law, policy and enforcement practices. Paulo Longo Research Initiative, Michael Kirby Centre for Public Health and Human Rights, Monash University, 2013.

[9] Organization, W. H., Preventing HIV among sex workers in sub-Saharan Africa: a literature review. 2011.

[10] Report, U. M., Condoms the prevention of HIV, other sexually transmitted infections and unintended pregnancies. SAHARA-J: Journal of Social Aspects of HIV/AIDS, 2016. 1 (1): p. 17481-184.

[11] Health. G, Health of female sex workers and their children. UNAIDS Report, 2016. 4: p. 18.

[12] Scheibe, A., F. Drame, and K. Shannon, HIV prevention among female sex workers in Africa. SAHARA-J: Journal of Social Aspects of HIV/AIDS, 2012.9 (3): p. 167-172.

[13] Tamene, M. M., G. A. Tessema, and G. K. Beyera, Condom utilization and sexual behavior of female sex workers in Northwest Ethiopia: A cross-sectional study. Pan African Medical Journal, 2015. 21 (1).

[14] Yam, E. A., et al., Use of dual protection among female sex workers in Swaziland. International perspectives on sexual and reproductive health, 2013: p. 69-78.

[15] M. D. S. A., Condom use among female sex workers and their noncommercial partners: Effects of a sexual risk intervention in two Mexican cities. NIH-PA Author Manuscript, 2012: p. 13.

[16] Andrews, C. H., et al., Determinants of consistent condom use among female sex workers in Savannakhet, Lao PDR. BMC women's health, 2015. 15 (1): p. 63

[17] Yam, E. A., et al., Pregnancy experiences of female sex workers in Adama city, Ethiopia: Complexity of partner relationships and pregnancy intentions. Studies in Family Planning, 2017. 48 (2): p. 107-119.

[18] Anteneh, Z. A., Y. A. Agumas, and M. Tarekegn, Sexually transmitted diseases among female commercial sex workers in Finote Selam town, northwest ethiopia: a community-based cross-sectional study. HIV/AIDS (Auckland, NZ), 2017. 9: p. 43.

[19] Nehl. J et. al Sex partner type, drug use and condom use selfefficacy among African Americans from disadvantaged neighborhoods: Are associations with consistent condom use moderated by gender? 2016 . 
[20] Lisa B. et. al Factors associated with condom use among men and women living with HIV in Lilongwe, Malawi: a cross sectional study 2017 .

[21] Abebe M. et. al Living with parents and risky sexual behaviors among preparatory school students in Jimma zone, South west Ethiopia 2013

[22] Hongjie L. et. al Chinese Culture, Homosexuality Stigma, Social Support and CondomUse A Path Analytic Model 2011.

[23] Jing G. et. al Social Environmental factors and condom use among female injection drug users who are sex workers in China 2014.

[24] Mohammed A. et. al Predictors of Condom Utilization in Plateau State, Nigeria 2017.

[25] Adebola A. et. al Social factors, social support and condom use behavior among young urban slum inhabitants in Southwest Nigeria 2008.
[26] Lagarde E. et. al Educational level is associated with condom use within non-spousal partnerships in four cities of subSaharan Africa.

[27] Getnet $\mathrm{M}$ et. al Patterns of knowledge and condom use among population groups: results from the 2008 Ethiopian behavioral surveillance survey.

[28] Kefale B. Knowledge, Attitude, Practice and Determinants of Condom Use Among People Living With HIV/AIDS in Gondar University Hospital, North West Ethiopia 2013.

[29] Habtamu A. Intention toward condom use and its associated factors among students of Debre Work Senior Secondary and Preparatory School, East Gojjam Zone, Ethiopia 2015.

[30] Andualem D. et. al Assessment of substance use and risky sexual behavior among Haramaya University Students, Ethiopia 2014. 